\title{
Water Based Nanofluids: A Computational Study on Temperature Distribution in a Pipe Flow
}

\author{
Md. Ebrahim Khalil Bhuiyan, Mohammad Mahmudur Rahman Khan*, Iqbal Mahmud \\ Department of Textile Engineering, Bangladesh University of Business and Technology, Dhaka, Bangladesh \\ Email: ^mahmud.rk@gmail.com, ^mahmud.r@bubt.edu.bd
}

How to cite this paper: Bhuiyan, Md.E.K., Khan, M.M.R. and Mahmud, I. (2017) Water Based Nanofluids: A Computational Study on Temperature Distribution in a Pipe Flow. Advances in Nanoparticles, 6, 141-147. https://doi.org/10.4236/anp.2017.64012

Received: August 9, 2017

Accepted: October 14, 2017

Published: October 17, 2017

Copyright $\odot 2017$ by authors and Scientific Research Publishing Inc. This work is licensed under the Creative Commons Attribution International License (CC BY 4.0).

http://creativecommons.org/licenses/by/4.0/

\begin{abstract}
Fluid containing nanometer-sized particles (i.e. nanoparticles) is known as nanofluid. Three different nanofluids flowing in a pipe with heat source at the inlet and sink in the walls are studied. The base fluid is water. $20 \mathrm{~nm}$ size nanoparticle $\mathrm{Al}_{2} \mathrm{O}_{3}$ is mixed with base fluid with volume concentrations of $0.1 \%$, $0.2 \%$ and $0.5 \%$. Simulation is done using ANSYS Workbench 17.1. The result shows correlation between concentration of nanoparticle and temperature gradient at the outlet of the pipe.
\end{abstract}

\section{Keywords}

Nanofluid, Nanoparticle, $\mathrm{Al}_{2} \mathrm{O}_{3}, \mathrm{CFD}$, ANSYS

\section{Introduction}

Nanofluids (nanoparticles fluid suspensions) [1] is the term introduced by Choi et al. [2]. Nanofluids based heat transfer fluids have better thermal properties than the host fluids. Solid nanoparticles such as metal or metal-oxide (ranging from 1 to $100 \mathrm{~nm}$ size) are diffused in traditional liquids e.g. water, ethylene glycol and engine oils etc. to prepare nanofluids. To gain highest possible thermal properties by dispersing nanoparticles (preferably less than $1 \mathrm{~nm}$ ) uniformly at small possible volume concentration (preferably less than 1\%) as well as maintaining a stable suspension is the main concern of nanofluids.

Transfer of heat energy has become a major task in industrial processes [3]. Heat must be added, removed or exchanged between process streams throughout various industrial processes. Study of nanofluid shows that it can be used as a high performance heat transfer medium. The diffused nanoperticles allow 
more heat transfer by increasing thermal conductivity of the nanofluids along with conduction and convection heat transfer coefficient. Behind the enhancement of thermal properties of nanofluids the main reasons are increment of relative surface area, effective thermal conductivity, mixing fluctuation and turbulence of the fluid and among others [3].

In this study, three different nanofluids were studied inside a pipe with flow and heat transfer.

\section{Problem Statement}

A situation is considered where fluid is flowing through a pipe. The pipe is connected with both source and sink. Then three different types of nanofluids are investigated in respect to their temperature distribution at the outlet. The base fluid is water, which has been investigated at first to compare the nanofluids results. Nanoparticle aluminum oxide is mixed with base fluid at volume concentrations $(0.1 \%, 0.2 \%$, and $0.5 \%)$ to create three different nanofluids. These liquid-solid nanofluids are treated as single fluid in Fluent using their representative thermal and physical properties. Experimental values [1] of the nanofluids have been used for this purpose (Table 1).

\subsection{Physical Model}

At the beginning a situation following the Example 8-3 [4] is reproduced using Fluent. Schematic diagram of the system is shown in Figure 1.

At the inlet fluid is flowing with a constant temperature. The pipe wall is always at $273.15 \mathrm{k}$ temperature as according to Example 8-3 [4], the pipe goes through an ice lake with temperature $273.15 \mathrm{k}$.

$0^{\circ} \mathrm{C}$

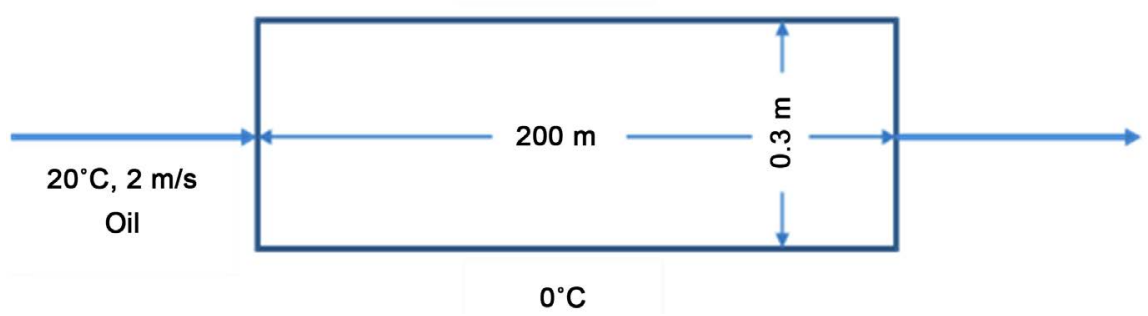

Figure 1. Schematic diagram of the system.

Table 1. Properties of nanofluids.

\begin{tabular}{cccc}
\hline \multirow{2}{*}{ Property } & \multicolumn{3}{c}{ Volume Concentration of $\mathrm{Al}_{2} \mathrm{O}_{3}$} \\
\cline { 2 - 4 } & $0.1 \% \mathrm{Al}_{2} \mathrm{O}_{3}$ & $0.2 \% \mathrm{Al}_{2} \mathrm{O}_{3}$ & $0.5 \% \mathrm{Al}_{2} \mathrm{O}_{3}$ \\
\hline Density $\rho\left(\mathrm{kg} / \mathrm{m}^{3}\right)$ & 1038 & 1042 & 1060 \\
Specific heat $C_{p}(\mathrm{j} / \mathrm{kg} \cdot \mathrm{k})$ & 3200 & 2600 & 500 \\
Thermal conductivity $K(\mathrm{~W} / \mathrm{m} \cdot \mathrm{k})$ & 0.6 & 0.615 & 0.65 \\
Viscosity $\mu(\mathrm{kg} / \mathrm{m} \cdot \mathrm{s})$ & 0.0007 & 0.00068 & 0.0006 \\
\hline
\end{tabular}


Continuity (Equation (1)), momentum (Equation (2)) and energy equations (Equation (3)) are solved to get result.

$$
\begin{gathered}
(\partial \rho / \partial t)+\nabla \cdot(\rho \boldsymbol{V})=0 \\
\rho(\partial \boldsymbol{V} / \partial t)+\rho(\boldsymbol{V} \cdot \nabla) \boldsymbol{V}=-\nabla \rho+\rho \boldsymbol{g}+\nabla \cdot \tau_{i j} \\
(\partial / \partial t) \int e^{*} \rho \mathrm{d} \forall+\int\left(\hat{u}+P / \rho+V^{2} / 2+g z\right) \rho \boldsymbol{V} \cdot \hat{n} \mathrm{~d} A=\dot{Q}_{\text {net in }}+\dot{W}_{\text {net in }}
\end{gathered}
$$

After reproducing, the result of Example 8-3, the properties of the fluid are changed to mimic nanofluids. Temperature gradient at the outlet of the pipe is studied and trend is identified with the volume concentrations of nano particles in the base fluid.

\subsection{Numerical Procedure}

Considered geometry is two-dimensional planar. For simplicity, 3D geometry is avoided, which is a consideration for future cases. $2500 \times 15$ mesh grid is used for this simulation. Simulation parameters are provided in Table 2.

The flow is calculated laminar for every case studied in this paper. Reynolds number is less than critical Reynolds number 2300 in all cases considered.

\subsection{Grid Size Convergence}

In order to avoid inaccurate result due to poor mesh density, different element numbers were used to analyze the mesh sensitivity. Three different element numbers (i.e., 1250, 3750, 37,500) have been used to compare temperature at the outlet of the pipe. It is found the element number converges after 3750 (Figure 2).

\section{Results}

Hagen-Poiseuille equation (Equation (4)) is used to compare the pressure drop along the pipe.

$$
\Delta p=\frac{8 \mu L Q}{\pi R^{4}}
$$

Table 2. Simulation parameters.

\begin{tabular}{cc}
\hline Solver-Type & Pressure based \\
\hline Solver-Time & Steady \\
Energy Model & On \\
Viscous Model & Laminar \\
Wall & Stationary \\
& Constant temperature \\
Solution method & Scheme: SIMPLE \\
& Energy: $2^{\text {nd }}$ order upwind \\
\end{tabular}




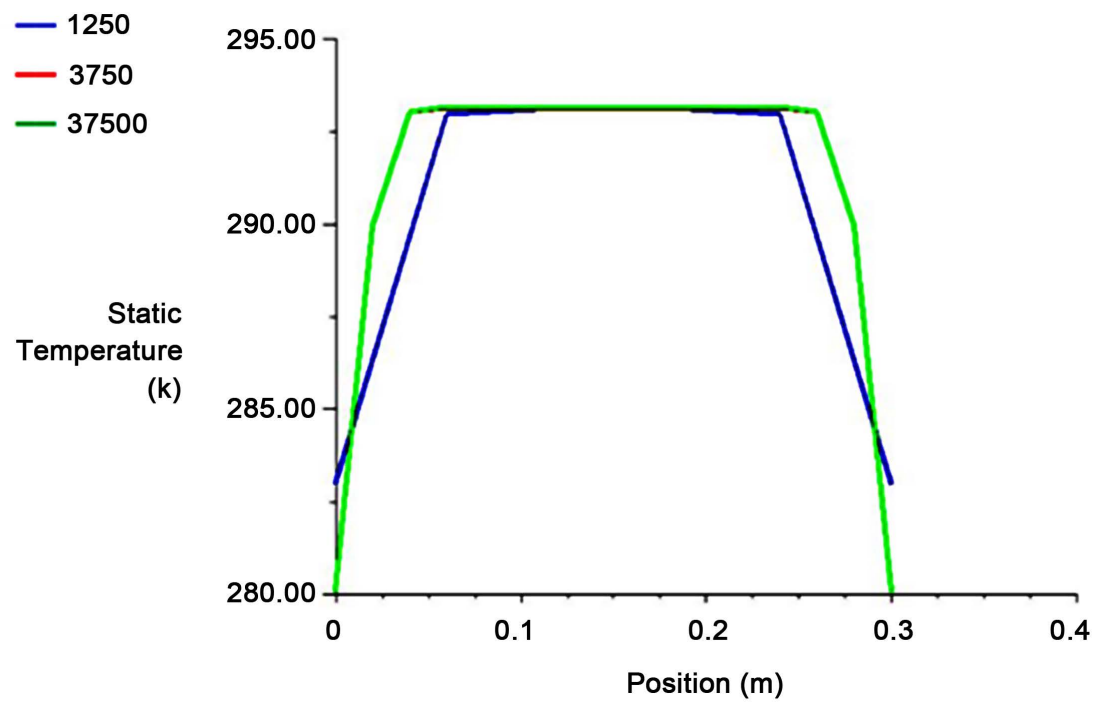

Figure 2. Mesh element convergence.

Here, $\mu$ (for water) $=0.001003 \mathrm{~kg} / \mathrm{m} \cdot \mathrm{s}, L$ (pipe length) $=200 \mathrm{~m}, v$ (fluid velocity) $=2 \mathrm{~m} / \mathrm{s}, R$ (pipe radius) $=0.15 \mathrm{~m}, Q$ (=area of pipe cross section $\times v)$ represents discharge rate. The pressure drop along the pipe $(\Delta p)$ is found $142.65 \mathrm{~Pa}$. The simulated result from Fluent is in close proximity of the calculated value (Figure 3).

Noticeably pressure fluctuates at the end of the pipe length. This happens due to the local back flow.

Equation (5) is used to calculate temperature at the end of pipe.

$$
\begin{gathered}
T_{e}=T_{s}-\left(T_{s}-T_{i}\right) \exp \left[-h A_{s} / \dot{m} C_{p}\right] \\
h=10.45-v+10 v^{1 / 2}
\end{gathered}
$$

Here, $T_{e}, T_{s}$ and $T_{i}$ represent temperatures of outlet, surface and inlet of the pipe respectively; $h$-convective heat transfer coefficient of water, $A_{s}$-surface area of pipe, $\dot{m}$-mass flow rate.

The calculated value of the temperature at the end of pipe is $302.93 \mathrm{~K}$ (Figure 4).

Flow is fully developed at some downstream distance of inlet (Figure 5). This distance is much higher than lower viscosity and dense fluid e.g. air (Figure 6).

\section{Analysis on Nanofluids}

At this point, the properties of the fluid are changed to mimic nanofluids. Experimental thermophysical properties of nanofluids were taken from [1]. Total four fluids were compared in terms of temperature gradient at the outlet of pipe (Figure 7). These are the base fluids water and three nanofluids, which are composition of water and three different volume fractions (i.e. $01 \%, 0.2 \%$, and $0.5 \%$ ) of aluminum oxide nano particles. Noticeably from pure water to with increasing volume fraction of nanoparticle, we see the wall temperature drops to 


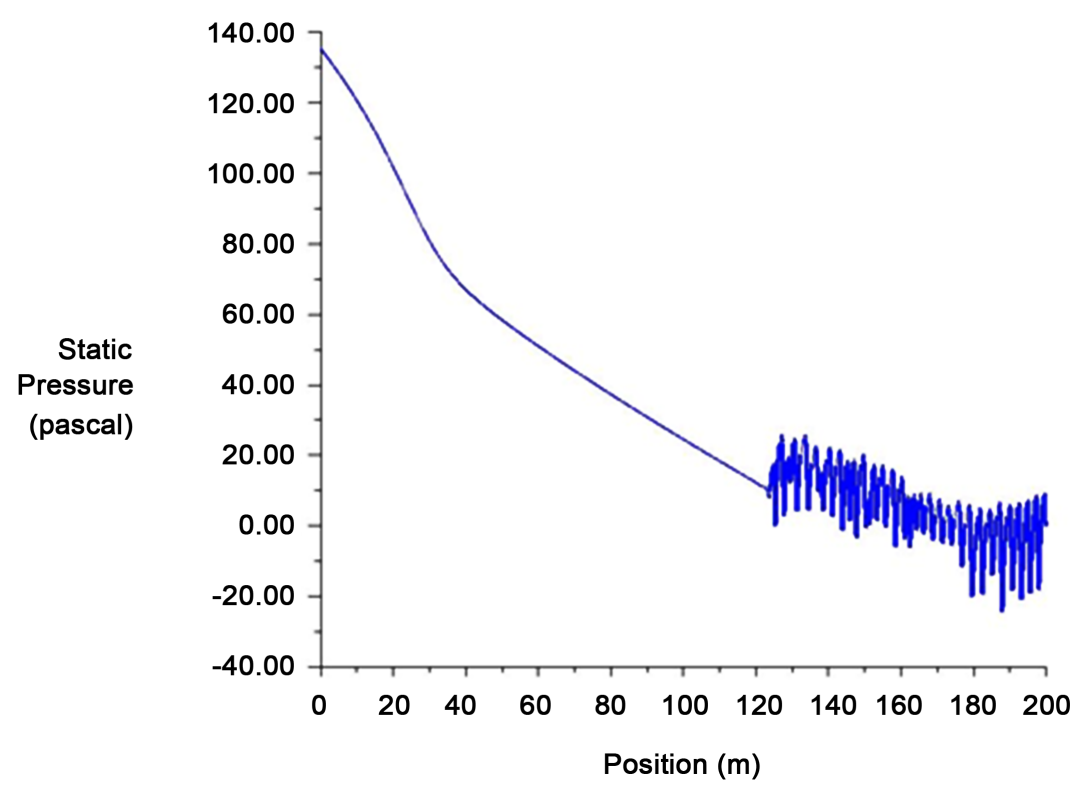

Figure 3. Pressure distribution along pipe axis (water).

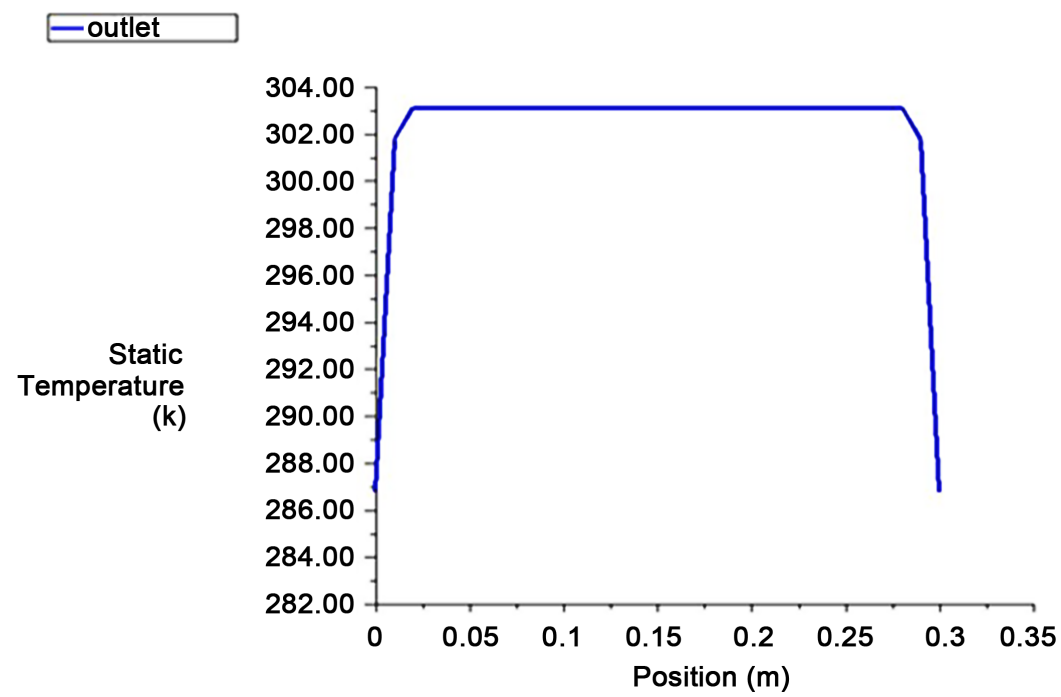

Figure 4. Temperature distribution at outlet (water).

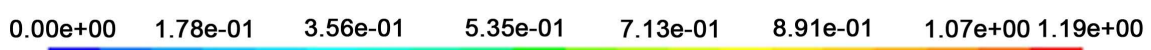

Figure 5. Velocity contours (Water). 

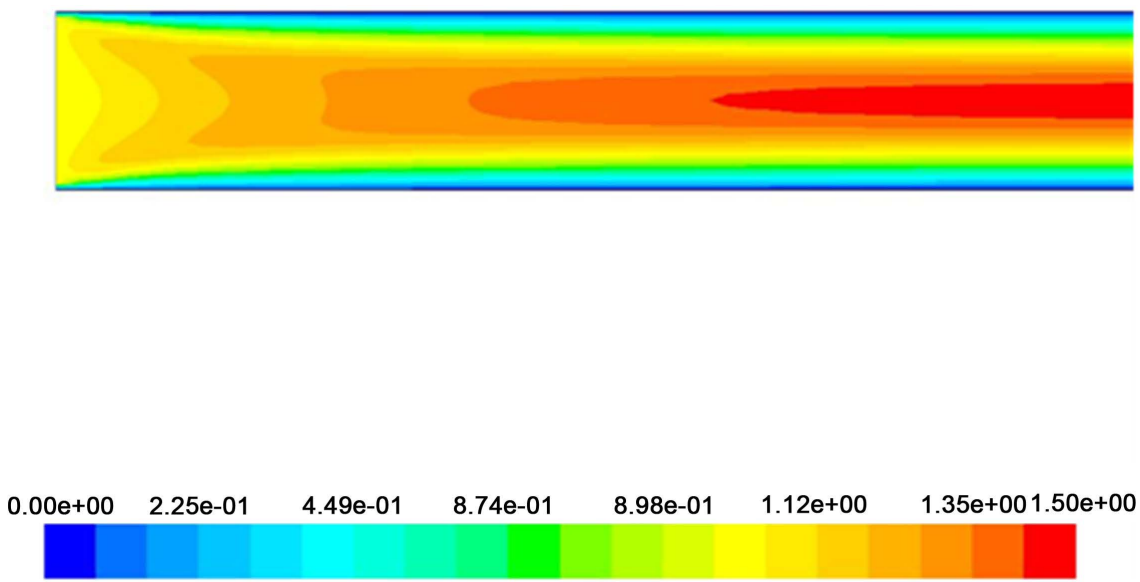

Figure 6. Velocity contours (air).

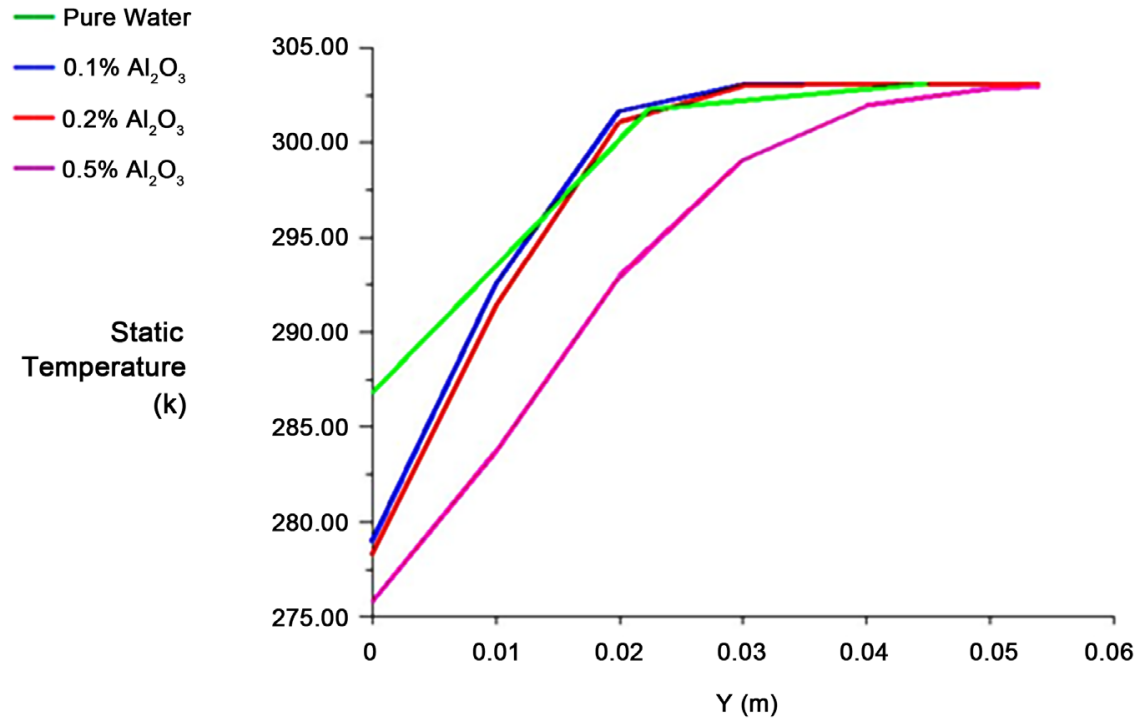

Figure 7. Temperature distribution at the outlet.

smaller values. This shows that with a very small amount of addition of nanoparticles, these nanofluids' thermal properties can be varied to a large extent.

\section{Conclusion}

After investigating three nanofludis in a pipe flow in terms of their temperature distribution at the outlet, it is found that with increasing volume fraction of aluminum oxide, temperature at the outlet wall decreases. The initial conclusion suggests that nanofluids have a potential to work as an industrial thermal fluid with superior thermophysical properties.

\section{References}

[1] Singh, K., Sharma, S. and Gangacharyulu, D. (2013) Experimental Study of Thermophysical Properties of $\mathrm{Al}_{2} \mathrm{O}_{3}$ /Water Nanofluid. IJRMET, 3, Issue 2.

[2] Choi, S. (1995) Enhancing Thermal Conductivity of Fluids with Nanoparticles. In: 
Siginer, D.A. and Wang, H.P., Eds., Development and Applications of Non-Newtonian Flows, Vol. 12, ASME, New York, 99-105.

[3] Sivashanmugam, P. (2012) Application of Nanofluids in Heat Transfer. In: Kazi, S.N., Ed., An Overview of Heat Transfer Phenomena, InTech. https://doi.org/10.5772/52496

[4] Cengel, Y.A. (2004) Heat Transfer: A Practical Approach. 2nd Edition, McGraw-Hill, New York. 